\title{
Common mental disorders in a young urban
}

\section{population in Colombia}

\author{
TRUDY HARPHAM, SIMON SNOXELL, EMMA GRANT \\ and CARLOS RODRIGUEZ
}

\author{
Background There are few studies of \\ mental ill health among young people in \\ developing countries.
}

\begin{abstract}
Aims To measure the prevalence of common mental disorders among lowincome young people in the city of Cali, Colombia and to examine associations with violence and social capital.
\end{abstract}

Method The Self-Reporting

Questionnaire was administered to 1057 young people aged I5-25 years. Social capital, violence, alcoholism and sociodemographic variables were also measured.

Results We found 255 young people (24\%) with common mental disorders. Being a woman, having limited education and experiencing high levels of violence were the main risk factors for common mental disorders. Social capital did not emerge as a risk factor.

Conclusions A large burden of mental ill health among young people was found; this requires urgent interventions and more research on the mechanisms which link mental health and violence.

Declaration of interest None. Funding detailed in Acknowledgements.
'There remains a need to fur ther increase understanding of the critical factors and influences which contribute to young people's mental health.' (Donald et al, 2000)

Although the heavy burden of mental ill health in developing countries has been recognised (World Health Organization, 1994), there are few studies on the mental health of young people. In a number of developing countries, political and economic conflict creates violent situations for young people in both the public and private spheres. This paper focuses upon one such area: Cali, Colombia. It presents the prevalence of mental ill health among low-income young people and examines associations with socio-demographic factors, social capital, alcoholism and violence. The hypotheses were that experience and perceptions of violence were directly associated with common mental disorders in young people, and that social capital was inversely associated with common mental disorders.

\section{METHOD}

Cali is one of the major cities in Colombia, with a population of approximately two million. It is a city in profound economic crisis, and has great inequalities across its 21 boroughs. The focus of the current study is the large very poor area located on the eastern fringe of the city and known as Aguablanca. This area has a population of around 500000 . The city, and particularly Aguablanca, has high homicide rates. In 2001, Cali's homicide rate was 90 per 100000 (Observatorio Social, 2003). Cali's young people are particular victims of this violence. In $2002,44 \%$ of the city's homicide victims were aged between 15 and 25 years (the age range of this study) (Observatorio Social, 2003). In Aguablanca, the unemployment rate is approximately $25 \%$, $28 \%$ live in poverty (defined as less than US $\$ 3.20$ per person per day), and around $30 \%$ of the total population of the borough are between 10 and 24 years of age (Municipality of Cali, 2000).

As this research was part of a quasiexperimental intervention study, the sampling was based on expected reductions in prevalence of key variables. Using a formula for the comparison of two proportions and given the possibility of cluster effects and refusals, a final sample size of 1168 was arrived at by assuming: a prevalence of key violence variables of $50 \%$ (as is the practice of CISALVA, the Violence Research Institute of the University of Valle, Cali); objectives of $10 \%$ reduction in the incidence of violence; and $30 \%$ reduction in perceptions of violence (StatCalc software, version 5.4 for Windows; AcaStat Software, Ashburn, Virginia, USA). Neighbourhood maps indicating dwellings were obtained from the city planning department. After field visits to update the maps, clusters of 20 dwellings were marked on the map; 116 clusters were randomly selected. If an eligible respondent (15-25 years old who had lived in the borough for at least 1 year) did not reside in the selected dwelling, the dwelling next door was approached until a young person within the selected age range was found. In each eligible dwelling, only one young person was interviewed. In dwellings where more than one eligible person was resident, the respondent was selected randomly by choosing the one whose first name began with a letter closest to the start of the alphabet. There was a $4 \%$ refusal rate, and a further 65 questionnaires were not administered because an upsurge in violence in the area threatened the safety of the field staff.

Interviewers were male and female local residents (from outside the study area) and over 18 years of age. The 37 interviewers were trained for 4 days and were monitored by 15 supervisors. Interviews (in Spanish) were conducted in private in the respondent's home in 2002.

Probable cases of common mental disorders (sometimes referred to as mental ill health below) were measured by the SelfReporting Questionnaire (SRQ-20) recommended by the World Health Organization for assessing the prevalence of depression and anxiety at the community level, where diagnoses of specific illness are not required (World Health Organization, 1994). The instrument, which consists of 20 'yes or no' questions, was administered by an interviewer, as it was anticipated that literacy rates might be low among some 
young people. Researchers had previously determined a cut-off point of $7 / 8$ for the SRQ-20 in Armero, Colombia (Lima et al, 1991). As this cut-off point was validated against DSM-III (American Psychiatric Association, 1980), it was used in the current study. Although the validation in Armero was in the context of a disaster, the $7 / 8$ cut-off has also emerged in numerous other studies using the SRQ-20 among low income, urban populations in Latin America (Harpham et al, 2003).

A wide range of socio-demographic, social capital and violence variables was also measured. The violence measurement tool was based on the ACTIVA questionnaire applied in many cities in Latin America (Orpinas, 1999). Questions cover: norms regarding violence inside and outside the home; the respondent's perpetration of violence against children, within the family and against a partner; being a victim and witness of violence outside the home; the respondent's perpetration of violence against non-household members; and consequences of violence in terms of feelings of insecurity and precautions taken. The social capital instrument drew on various sources, including the Social Capital Assessment Tool (developed by the World Bank, Krishna \& Schrader, 1999) and the World Values Survey (http:// www.worldvaluessurvey.org). Questions were designed to assess different dimensions of social capital, including: trust in institutions, the wider community and immediate neighbours and friends; perceptions of social cohesion concerning neighbourly unity and mutual respect; perceptions of solidarity involving support and reciprocity; perceptions of informal social control, meaning willingness and capacity to participate in collective action for communal benefit; and perception of civic participation. Social capital was measured at the individual level, not the ecological level. Attitudinal or perception variables were measured by a five-point Likert scale ranging from 'strongly disagree' to 'strongly agree'. Behavioural variables were coded 'never', 'once' or 'more than once' in relation to a specific recall period (for example, 'in the past year').

The CAGE instrument was used to test probable alcoholism. Validated in Spain, CAGE consists of four simple binary questions combined to form a scale in which answering positively to more than one item is defined as a 'high probability of alcoholism' or a 'case'. The instrument has high sensitivity $(65-100 \%)$ and specificity (88-100\%) (Martin Centeno \& Ojano, 2001). It is named CAGE because of the four items incorporated: cutting down drinking; annoyance at others' concern about drinking; guilt about drinking; and needing an eye-opener in the morning.

Reliability was tested by reapplying questionnaires to $5 \%$ of respondents within 2 days, using different interviewers. Spearman's correlation coefficient indicated that a good level of reliability had been achieved; $70 \%$ of items had coefficients $>0.70$ with the following differences between sections of the questionnaire: in the social capital instrument $67 \%$ of items had a coefficient $>0.70$, in the violence instrument $97 \%$ of items had a coefficient $>0.70$, for mental health $70 \%$ of items were $>0.70$ and for CAGE $75 \%$ were $>0.70$.

Factor analysis was used on the violence and social capital variables, respectively. In the social capital factor analysis, group membership was not included, as the dimension consisted of only one item (number of non-violent groups participated in). When a variable was measured by a Likert scale, if $80 \%$ or more of the sample fell within the 'strongly agree/agree' or 'strongly disagree/disagree' categories then the item was excluded owing to non-discriminatory power.

The association of demographic factors, social capital factors and violence factors with common mental disorder (case/non-case) was examined by logistic regressions.

The research also included 16 focus groups of young people from 15 to 25 years interviewed in Spanish in early 2004. Focus groups were divided by age and led by professionals experienced in working with young people. For reasons of sensitivity, discussions did not concentrate on the mental health of the participants but rather on their views of social capital and violence in the family and neighbourhood.

\section{RESULTS}

The overall prevalence of common mental disorders was $24 \%$ (255/1057). Tables 1 , 2 and 3 show the percentage of probable cases and non-cases of common mental disorders in relation to socio-demographic variables and alcohol misuse, social capital and violence variables, respectively. Tables
2 and 3 also indicate which variables (items) went into which factors in the factor analyses of social capital and violence.

\section{Logistic regression}

Table 4 presents the results of the logistic regression.

\section{Model I}

In the first model, only demographic variables and alcohol use were entered. The population categories most at risk of common mental disorders are women, those with low education, those working in the informal sector (i.e. in irregular, insecure, often unskilled employment) and those with alcohol misuse.

\section{Model 2: adding social capital}

Social capital factors (see Table 2) and the group membership scale were added into the second model. The criterion for entry $(P$ value) was also changed from 0.05 to 0.06 , slightly decreasing the confidence level. Alcoholism dropped out, and coming from outside Cali and living in inadequate housing entered the model as risk factors. People who had high levels of 'thin trust' (general trust in people from the neighbourhood, as opposed to 'thick trust' which refers to a concentration of trust among a few specific people) were found to be less likely to suffer from mental health problems. Socio-demographic risk factors remained the same as in model 1.

Table I Probable cases $(n=255)$ and non-cases $(n=802)$ of common mental disorders in relation to socio-demographic variables and alcohol misuse

\begin{tabular}{|c|c|c|}
\hline $\begin{array}{l}\text { Socio-demographics/ } \\
\text { alcohol misuse }\end{array}$ & $\begin{array}{c}\text { Non-cases } \\
\%\end{array}$ & $\begin{array}{c}\text { Cases } \\
\%\end{array}$ \\
\hline Women & 51 & 77 \\
\hline I5-20 years old & 69 & 77 \\
\hline Religious & 26 & 25 \\
\hline Have children & 33 & 41 \\
\hline In no fixed employment & 84 & 91 \\
\hline $\begin{array}{l}\text { Not completed } \\
\text { secondary school }\end{array}$ & 67 & 77 \\
\hline Overcrowded housing' & 83 & 78 \\
\hline Female-headed household & 37 & 40 \\
\hline Family from Cali & 56 & 52 \\
\hline Alcohol misuse & 15 & 21 \\
\hline
\end{tabular}

I. Measured by three people or more sleeping per room. 
Table 2 Probable cases $(n=255)$ and non-cases $(n=802)$ of common mental disorders in relation to social capital variables

\begin{tabular}{|c|c|c|c|}
\hline Dimension & Statement & $\begin{array}{c}\text { Non-cases } \\
\% \text { who agree } \\
\text { with statement }\end{array}$ & $\begin{array}{c}\text { Cases } \\
\% \text { who agree } \\
\text { with statement }^{\prime}\end{array}$ \\
\hline \multirow[t]{6}{*}{ Trust in institutions ${ }^{2}$} & The church provides a service whenever the community needs it & 95 & 92 \\
\hline & The school provides a service whenever the community needs it & 84 & 80 \\
\hline & The health centre provides a service whenever the community needs it & 77 & 76 \\
\hline & The police provide a service whenever the community needs it & 43 & 37 \\
\hline & The borough council provides a service whenever the community needs it & 7I & 73 \\
\hline & The neighbourhood council provides a service whenever the community needs it & 58 & 53 \\
\hline \multirow[t]{7}{*}{ Trust in people ${ }^{3}$} & There are neighbours in whom you can confide personal matters & 45 & 45 \\
\hline & There are neighbours with whom you can leave the keys of your house & 87 & 87 \\
\hline & There are neighbours with whom you can leave a family member & 91 & 88 \\
\hline & The majority of neighbours don't gossip maliciously about people & 20 & 13 \\
\hline & The majority of neighbours would return a lost wallet if they find it & 23 & 23 \\
\hline & The majority of neighbours don't take advantage of people & 38 & 33 \\
\hline & People trust other neighbours & 50 & 35 \\
\hline \multirow[t]{4}{*}{ Social cohesion ${ }^{4}$} & People know each other & 90 & 87 \\
\hline & People get on with each other & 59 & 50 \\
\hline & People are close & 39 & 33 \\
\hline & People often visit each other & 53 & 55 \\
\hline \multirow[t]{4}{*}{ Solidarity ${ }^{4}$} & There are neighbours who would support you if something unfortunate happened to you & 90 & 90 \\
\hline & There are neighbours who would help you financially if you lost your income & 48 & 41 \\
\hline & There are neighbours who would give you information about the neighbourhood & 87 & 85 \\
\hline & There are neighbours who would tell you about a work opportunity & 77 & 70 \\
\hline \multirow[t]{8}{*}{ Social control } & People would get together to intervene in problems between neighbours & 52 & 58 \\
\hline & People would get together to improve the security of the area & 72 & 74 \\
\hline & People would get together to demand better health services & 80 & 80 \\
\hline & People would get together to improve the image of the neighbourhood & 80 & 80 \\
\hline & People would get together to prevent rubbish accumulation & 83 & 81 \\
\hline & People would get together to prevent drug use in public places & 61 & 59 \\
\hline & People would get together to demand better schools & 77 & 81 \\
\hline & People would get together to report corruption within institutions & 68 & 67 \\
\hline \multirow[t]{5}{*}{ Civic participation ${ }^{5}$} & Local residents frequently talk to authorities or local organisations & 73 & 73 \\
\hline & People in this area vote in the local elections for mayor & 94 & 93 \\
\hline & People in this area actively participate in electoral campaigns & 88 & 83 \\
\hline & People participate in marches & 72 & 69 \\
\hline & People vote in borough and neighbourhood elections & 88 & 84 \\
\hline
\end{tabular}

I. All percentages include 'strongly agree' and 'agree' from a five-point Likert scale.

2. In the factor analysis, trust in institutions was broken down into trust in state and trust in community institutions.

3. Trust in people was broken down into thin and thick trust (see text).

4. Social cohesion and solidarity emerged as one factor.

5. Civic participation was broken down into neighbours' versus the respondent's participation.

\section{Model 3: adding violence}

Model 3 incorporates all the violence factors (see Table 3). Housing quality and thin trust (the only significant social capital factor) dropped out. Being a woman, having a low level of education, earning a living in the informal sector (as opposed to the formal sector), and being a migrant remained as risk factors. Three violence items entered as risk factors: being a victim of neighbourhood violence, experiencing violence in the family and suffering the consequences of violence.
Summary

The models demonstrate that being a woman, having a low level of education and experiencing high levels of violence (both in the home and in the public sphere) are risk factors for common mental 
Table 3 Probable cases $(n=255)$ and non-cases $(n=802)$ of common mental disorders in relation to violence variables

\begin{tabular}{|c|c|c|c|}
\hline Dimension & Statement & $\begin{array}{c}\text { Non-cases } \\
\% \text { who agree } \\
\text { with statement }^{\prime}\end{array}$ & $\begin{array}{c}\text { Cases } \\
\% \text { who agree } \\
\text { with statement }\end{array}$ \\
\hline Norms of violence & It is necessary to shout at a child & 53 & 61 \\
\hline \multirow[t]{5}{*}{ inside the home $e^{1,5}$} & It is acceptable for an adult to hit a child & 50 & 48 \\
\hline & It is acceptable for a man to slap his partner & II & 14 \\
\hline & It is acceptable for a woman to slap her partner & 31 & 37 \\
\hline & If a woman is unfaithful to her partner, he has the right to hit her & 21 & 28 \\
\hline & If a man is unfaithful to his partner she has the right to hit him & 24 & 34 \\
\hline Norms of violence & A person has the right to kill to defend his/her family & 28 & 31 \\
\hline \multirow[t]{5}{*}{ outside the homel } & A person has the right to kill to defend his/her house & 24 & 28 \\
\hline & It is acceptable to kill people who are a threat to the community & 25 & 34 \\
\hline & If the authorities are weak, people have the right to take the law into their own hands & 42 & 43 \\
\hline & Carrying a weapon makes a person safer & 28 & 30 \\
\hline & A person has the right to steal to feed his/her family & 23 & 26 \\
\hline Violence against & Shouted angrily at a child & 55 & 72 \\
\hline \multirow[t]{2}{*}{ children ${ }^{2,3}$} & Smacked a child & 43 & 55 \\
\hline & Hit a child with a belt, cable or other hard object & 23 & 31 \\
\hline Violence within & Shouted angrily at an adult member of the fmaily & 41 & 58 \\
\hline \multirow[t]{5}{*}{ the family ${ }^{2}$} & Been angrily shouted at by a family member & 66 & 82 \\
\hline & Threatened to hurt an adult member of the family & 7 & 13 \\
\hline & Someone in the family has threatened to hurt him/her & II & 26 \\
\hline & Hit an adult family member & 5 & 13 \\
\hline & Someone in the family has hit him/her & 17 & 32 \\
\hline \multirow[t]{2}{*}{ Partner violence ${ }^{1,4}$} & Shouted furiously at a partner & 51 & 67 \\
\hline & Been furiously shouted at by a partner & 44 & 63 \\
\hline Victim of violence & Been insulted by someone in the area & 37 & 54 \\
\hline \multirow[t]{4}{*}{ outside the home ${ }^{2}$} & Been hit & 6 & 15 \\
\hline & Been wounded & 4 & 8 \\
\hline & Been robbed & 19 & 19 \\
\hline & Someone from the neighbourhood has threatened to hurt him/her or someone in his/her family & 18 & 32 \\
\hline Witness of violence & Seen someone being robbed in the neighbourhood & 74 & 80 \\
\hline \multirow[t]{5}{*}{ outside the house ${ }^{2}$} & Seen someone being attacked or hit & 67 & 77 \\
\hline & Know someone in the neighbourhood who has been threatened & 41 & 57 \\
\hline & Know someone in the neighbourhood who has been wounded & 54 & 7I \\
\hline & Know someone in the neighbourhood who has been murdered & 60 & 74 \\
\hline & Know someone in the neighbourhood who has been a victim of sexual abuse & 16 & 29 \\
\hline Perpetrator of & Insulted anyone & 41 & 58 \\
\hline violence outside & Threatened to harm anyone & 9 & 16 \\
\hline \multirow[t]{2}{*}{ the home ${ }^{2}$} & Hit another person & 20 & 32 \\
\hline & Used force to make anyone do something which s/he wanted them to do & 6 & II \\
\hline Consequences of & Not been able to enjoy the recreational activities to which $\mathrm{s} /$ he is accustomed & 93 & 88 \\
\hline violence outside & It is safer to move somewhere else & 93 & 88 \\
\hline \multirow[t]{3}{*}{ the home ${ }^{2}$} & It is dangerous to go out at night & 93 & 88 \\
\hline & The house's security should be improved & 96 & 95 \\
\hline & There are more places in the neighbourhood that should be avoided & 93 & 89 \\
\hline
\end{tabular}

I. Respondents who answered 'strongly agree' or 'agree'.

2. Respondents who answered 'once' or 'more than once'.

3. Recall period of month. All other items are asked with a I year recall period.

4. Only those respondents with partners are included: $n=508$ (non-cases), $n=164$ (cases).

5. In the factor analysis, 'norms of violence inside the home' was broken down into norms relating to violence against child and partner respectively. 
Table 4 Mental health logistic regression models

\begin{tabular}{|c|c|}
\hline Model & $\begin{array}{c}\operatorname{Exp}(\mathrm{B}) \\
(95 \% \mathrm{Cl})\end{array}$ \\
\hline \multicolumn{2}{|l|}{ I } \\
\hline Constant & $0.15^{* * *}$ \\
\hline Gender: female & $4.10 * * *(2.87-5.89)$ \\
\hline Education: completed secondary and other advanced studies & $0.48 * * *(0.30-0.75)$ \\
\hline Works in informal sector for living & $1.58 * *(1.10-2.26)$ \\
\hline Works in formal sector for living & $0.69 * *(0.403-1.17)$ \\
\hline Education: some secondary & $0.75^{* *}(0.50-1.18)$ \\
\hline Alcohol misuse & $1.57 *(1.06-2.32)$ \\
\hline \multicolumn{2}{|l|}{2} \\
\hline Constant & $0.21 * * *$ \\
\hline Gender: female & $3.75 * * *(2.59-5.42)$ \\
\hline Works in informal sector for living & $1.64^{* *}(1.13-2.37)$ \\
\hline Education: completed secondary and other advanced studies & $0.52 * *(0.32-0.84)$ \\
\hline Poor-quality housing & $1.48 *(1.05-2.11)$ \\
\hline Migrant & $1.37 *(1.01-1.87)$ \\
\hline High 'thin' trust' & $0.81 *(0.66-1.00)$ \\
\hline \multicolumn{2}{|l|}{$3^{2}$} \\
\hline Constant & $0.01 * * *$ \\
\hline Gender: female & $4.03^{* * *}(2.75-5.89)$ \\
\hline Feels consequences of violence & $\mathrm{I} .5 \mathrm{I} * * *(\mathrm{I} .2 \mathrm{I}-\mathrm{I} .89)$ \\
\hline Victim of family violence & $1.77^{* * *}(1.33-2.36)$ \\
\hline Victim of neighbourhood violence & $1.81^{* * *}(1.36-2.40)$ \\
\hline Education: completed secondary and other advanced studies & $0.49 * *(0.30-0.80)$ \\
\hline Migrant & $1.41 *(1.02-1.94)$ \\
\hline Works in informal sector for living & $\mathrm{I} .5 \mathrm{I} *(\mathrm{I} .3-2.2 \mathrm{I})$ \\
\hline
\end{tabular}

$* P<0.05, * * P<0.01, * * * P<0.001$.

I. See text for definition of 'thin' trust.

2. Model excludes the partner violence factor.

disorders. Owing to the prominence of the gender factor, we conducted a separate multivariate analysis, not reported in full here, of the relationship between gender and violence. Gender was not independently associated with witnessing, being a victim of, or suffering the consequences of violence, but men were significantly more likely to perpetrate violence.

\section{DISCUSSION}

\section{Comparing the quantitative and qualitative findings}

Given the growing number of studies that link poverty with common mental disorders it is perhaps surprising that few of the proxy variables for poverty (except lack of education and working in the informal sector) emerge as significant in the quantitative research. In the qualitative research, poverty emerged as a major cause of tensions in the public and domestic domains. Here one young person describes tensions in the family:

'There are households that have good relations inside, and there are the majority where there are problems, and honestly in those moments, the distorting factor is money, because they are all living on top of one another, so there is no money, they are not working, so the bills come in and so the mother gets desperate and starts being sarcastic and the kids answer back and this is what leads to the breakdown in household harmony'.

The fact that being a migrant was associated with mental ill-health is in accordance with focus group participants who often attributed the severe strain experienced by migrants to poverty and discrimination (although interestingly family origins or ethnicity did not emerge as a significant risk factor). Other socio-demographic variables, such as age and religion, were not associated with caseness either. Being a woman was the most important demographic risk factor - a finding that matches other studies (see below).

The prevalence of alcohol misuse was $15 \%$, which is high compared with a CAGE study of Colombians of 12-60 years, which found $7 \%$ to be probable alcoholics (Centro de Estudies e Información en Salud, 1996). Indeed focus group participants spoke openly and frequently of alcohol problems in their families and among neighbours. However, alcoholism did not emerge as significant in the final model.

In terms of social capital, focus group participants tended to describe relatively low generalised trust among residents of the community, higher trust in immediate neighbours, relatively high solidarity and social cohesion and moderate levels of social control and civic participation. Although they made few specific links with mental health, it is noteworthy that gossip between neighbours was often blamed for causing stress and frustration among young people. For one focus group participant such gossip is based on 'anger, envy, men and women' (Commune 14, 19-25 years). Another complains: 'they are envious of us because we have a house' (Commune 14, 19-25 years). In the regression, none of the social capital factors was ultimately associated with common mental disorders.

Although having norms that condoned violence was not associated with common mental disorders, the perpetration of violence, whether in the home, against a child or partner, or on the street, was associated with poor mental health. Reports of perpetration of violence, victimisation and witnessing violence inside and outside the home indicate that violence is a part of everyday life for many young people: $25 \%$ had hit a child with a hard object in the past month; $20 \%$ had been hit by someone in their family during the past year; $23 \%$ had hit someone in the past year; and $63 \%$ knew someone who had been murdered in the past year. Discussions in focus groups suggest that these figures may even be under-reported, especially in terms of perpetration of violence and violence in the family. There does arise the question of whether there is a cultural norm of boasting about violence. The responses to the questions about norms of violence (which often condemned violence) suggested that this bias was not likely, and interviewers certainly did not perceive any. Being a victim of violence within the family was associated with common mental disorders. During focus groups concentrating on family 
issues, young people themselves expressed the stresses that family violence imposed on them and their siblings. Similarly, being a victim of violence outside the home was associated with mental ill health. The consequences of violence (feelings of insecurity) were also associated significantly with common mental disorders. Nearly all focus group participants expressed feelings of insecurity.

\section{Putting the results into context - comparisons with other studies}

In many developed countries the major burden of disease for young people is mental ill health (Moon et al, 1999). In developing countries there are few goodquality data on the burden of mental ill health among young people, relative to other risks such as accidents, homicides or infectious diseases. More population-based surveys of young people (a neglected age group in international health apart from the consideration of the reproductive health of young women) covering both physical and mental health are needed. The $24 \%$ prevalence of mental ill health found in our study is high compared with other low-income, mixed-gender, mixed-age urban populations in developing countries (Harpham et al, 2003). The poverty and demographic profile of the low-income urban young person in Cali are similar to those of young people in many other Latin American cities (and in some cities from other developing countries acknowledged to have striking similarities to Latin American cities - for example, Johannesburg in South Africa). The violence levels are probably higher than in many cities, but the relationships identified between violence and mental health in our study may be generalisable to other young people living in increasingly violent environments. Studies such as this begin to explore the associations between different factors and the mental health of young people. In terms of socio-demographic variables, this study confirms the common finding that young women (as in Donald et al, 2000), young people with alcohol misuse (Manchester City Council, 2004) and less educated young people have higher levels of mental ill health.

We found that experiencing violence is associated with mental health problems. This confirms the findings of Mazza \& Reynolds (1999) and the Canadian Mental

\section{CLINICAL IMPLICATIONS}

- The burden of mental ill health among low-income urban young people in Cali, Colombia is particularly high for women and those with limited schooling. Interventions could target these groups.

Mental ill health is associated with a wide range of experiences of violence. Interventions to reduce violence may improve mental health.

Mental health is associated with some elements of social capital, which suggests that a social model of intervening to improve mental health is appropriate.

\section{LIMITATIONS}

- Only one community/geographical area was studied, therefore the relative importance of contextual (community) versus compositional (individual) effects could not be examined (i.e. there was no multi-level modelling).

- As the research was not longitudinal it was not possible to identify causal relations. Does depression cause violence or violence cause depression? Reverse causality is a potential problem, i.e. those who are depressed may evaluate their surroundings negatively and have reduced coping skills that may lead to violence.

- There is a potential bias due to the fact that individuals who are depressed and/or anxious may tend to perceive things (cohesion, trust and support) in a way that might not reflect real ('objective') levels of these features of a community.

TRUDY HARPHAM, PhD, SIMON SNOXELL, MSc, EMMA GRANT, PhD, London South Bank University, London, UK; CARLOS RODRIGUEZ, MSc, Fundaps (Consulting Foundation in Health and Social Development Programmes), Cali, Colombia

Correspondence: Professor Trudy Harpham, London South Bank University, 103 Borough Road, London SEI OAA, UK. E-mail: t.harpham@isbu.ac.uk

(First received 30 July 2004, final revision 9 December 2004, accepted 21 December 2004)

Health Association (2003). Some health researchers have linked this association to the experience of overwhelming shame and humilitation and suggest that vulnerability to violence is influenced by psychological defence mechanisms (Gilligan, 2000). It is also tempting to speculate that the huge economic inequities faced in Latin American cities, especially those with pronounced poverty such as Cali, can lead to anger, frustration and hopelessness, which can prompt both violence and depression/anxiety. This is perhaps particularly true for young people. The mechanisms linking violence and mental ill health are likely to be numerous and have reverse causalities built in. For example, experiencing violence may cause depression which, in turn, may increase long-term difficulties (e.g. cause unemployment or break up with partner). One may speculate that this spiralling down may prompt different norms regarding the acceptability of violent behaviour and thus may, in the long term, lead to violent behaviour itself. This area of the linkages between violence and mental health among young people in conditions of poverty requires more qualitative research to inform potential intervention programmes.

Our findings were less definite concerning the relationship between social capital and mental health in young people. Some research has shown links between social capital and mental health (McKenzie et al, 2002). However, Lomas (1998), Harpham et al (2002) and Edmondson (2003) concur that although there are hypotheses that 
social capital may influence mental health, there is a lack of empirical research. We found that in the context of conflict in Cali, violence may have a greater influence than social capital on the mental ill health of young people. In less violent environments, the importance of social capital in influencing mental ill health may be more pronounced.

\section{Action to reduce violence and improve mental health}

In contrast to the public health approach, which mainly aims to reduce individual risk factors through behaviour modifications, a new approach to violence reduction is to strengthen social capital (Moser \& Schrader, 1999). This follows from the multi-level study of Sampson et al (1997) in Chicago, which found that high levels of social cohesion were linked to reduced violence. In terms of policy and practice, can social capital be strengthened to reduce violence and improve the mental health of young people? We are working with youth, community based organisations and the municipal department in Cali to test this theory.

\section{ACKNOWLEDGEMENTS}

Research was funded by the United States National Institute of Mental Health and the Office of Behavioural Social Sciences Research (exploratory/ development grant no. I R2I MH62895-0I).

\section{REFERENCES}

Canadian Mental Health Association (2003) Violence and Mental IIIness. Toronto: CMHA. Available at: http: / www.cmha.ca/english/info_centre/mh_pamphlets /

mh_pamphlet_vmi.htm.

Centro de Estudios e Información en Salud (CEIS) de la Fundación Santafé de Bogotá (1996) Segunda Encuesta Nacional Sobre Consumo de Alcohol, Tabaco y Sustancias Psicoactivas en Colombia. Bogotà: CEIS.

Donald, M., Dower, J., Lucke, J., et al (2000) The Queensland Young People's Mental Health Survey Report. Queensland: University of Queensland.

Edmondson, R. (2003) Social capital: a strategy for enhancing health? Social Science and Medicine, 57, 1723-1733.

Gilligan, I. (2000) Violence in public health and preventative medicine. Lancet, 355, 1802-1803.

Harpham, T., Grant, E. \& Thomas, E. (2002) Measuring social capital within health surveys: key issues. Health Policy and Planning, 17, 106-III.

Harpham, T., Reichenheim, M., Oser, R., et al (2003) Measuring mental health in a cost-effective manner. Health Policy and Planning, 18, 344-349.

Krishna, A. \& Schrader, E. (1999) Social Capital Assessment Tool.Washington, DC: World Bank.

Lima, B., Pai, S., Santacruz, H., et al (1991) Psychiatric disorder among poor victims following a major disaster - Armero, Colombia. Journal of Nervous and Mental Disease, 47, 7-17.

Lomas, J. (1998) Social capital and health: implications for public health and epidemiology. Social Science and Medicine, 47, $\mid 181-1188$.

Manchester City Council (2004) Mental Health. Manchester, UK: MCC. Available at: http:// www.manchester.gov.uk/health/jhu/intelligence/ reports/mental.htm
Martin Centeno, A. \& Ojano, C. (200I) El medico de atención primaria en la prevención y tratamiento de los problemas relacionados con el consumo de alcohol. Medicina General, 32, 233-240.

Mazza, J. J. \& Reynolds, w. M. (1999) Exposure to violence in young inner-city adolescents: relationships with suicidal ideation, depression, and PTSD symptomatology. Journal of Abnormal Child Psychology, 27, 203-213.

McKenzie, K., Whitley, R. \& Weich, S. (2002) Social capital and mental health. British Journal of Psychiatry, I8I, 280-283.

Moon, L., Meyer, P. \& Gran, J. (1999) Australia's Young People: Their Health and Well-Being. Canberra: Australia Institute of Health and Welfare.

Moser, C. \& Schrader, E. (1999) A Conceptual Framework for Violence Reduction. Washington DC: World Bank.

Municipality of Cali (2000) Cali en Cifras. Cali: Municipal Department.

Observatorio Social, Secretaria de Gobierno, Convivencia y Seguridad, Alcaldía Santiago de Cali (2003) Informe: Primer Semestre 2003 en la Ciudad de Cali. Santiago de Cali Colombia: Observatorio Social, Secretaria de Gobierno, Convivencia y Seguridad, Alcaldía Santiago de Cali.

Orpinas, P. (1999) Who is violent? Factors associated with aggressive behaviours in Latin America and Spain. Revista Panamericana de la Salud Pública, 5, 232-244.

Sampson, R., Raudenbush, S. \& Earls, F. (1997) Neighbourhoods and violent crime: a multi-level study of collective efficacy. Science, 227, 918-924.

World Health Organization (1994) User's Guide to the Self-Reporting Questionnaire (SRQ). Geneva: World Health Organization. 